\title{
Right Heart Failure in Different Left Ventricular Assist Devices: Single-Center Experience
}

\author{
Aditya Bansal, MD, ${ }^{1,2}$ David Schexnayder, MD,, ${ }^{1,2}$ Faisal Akhtar, MD, ${ }^{1,2}$ Arnav Bansal, ${ }^{1}$ Cruz Velasco-Gonzalez, PhD, ${ }^{3}$ \\ Arjun Verma, ${ }^{1}$ Michael Bates, MD, ${ }^{1,2}$ Patrick E. Parrino, MD, ${ }^{1,2}$ Sapna Desai, MD, ${ }^{4}$ Jay K. Bhama, MD ${ }^{5}$ \\ ${ }^{1}$ Department of Cardiothoracic Surgery, Ochsner Clinic Foundation, New Orleans, LA ${ }^{2}$ The University of Queensland Faculty of Medicine, \\ Ochsner Clinical School, New Orleans, LA ${ }^{3}$ Center for Applied Health Services Research, Ochsner Clinic Foundation, New Orleans, LA \\ ${ }^{4}$ Section of Heart Failure, Department of Cardiology, Ochsner Clinic Foundation, New Orleans, LA ${ }^{5}$ Department of Cardiothoracic Surgery, \\ University of lowa Health Care, lowa City, IA
}

Background: Right heart failure (RHF) following left ventricular assist device (LVAD) implantation increases morbidity and mortality for those who develop this complication. The purpose of this study was to assess the differences in incidence of RHF and outcomes between 2 types of continuous-flow LVADs at a single center.

Methods: From January 2012 through June 2016, 184 patients were implanted with a continuous-flow LVAD (161 patients with the HeartMate II and 23 patients with the HeartWare device) either as a bridge to transplant or as destination therapy. Preoperative demographics, medical history, laboratory values, hemodynamics, and device type were analyzed to determine the variables associated with RHF and mortality.

Results: Preoperative variables between the 2 groups were homogeneous. Most patients were Interagency Registry for Mechanically Assisted Circulatory Support profile 1 or 2 (92\%) and New York Heart Association class IV (81\%). More patients in the HeartMate II group had the indication of destination therapy (54\% vs 30\%), while more patients in the HeartWare group were implanted as bridge to transplant (70\% vs $46 \%$ ). RHF occurred in $57 \%$ of HeartWare patients compared to $16 \%$ of patients who received the HeartMate II $(P=0.0001)$. After propensity score analysis, patients receiving the HeartWare device had increased odds for RHF $(P=0.0013)$ and renal failure requiring dialysis $(P=0.0135)$. The HeartMate II patient survival rate exceeded the HeartWare patient survival rate at 1 year ( $82.1 \%$ vs $67.2 \%)$ and at 2 years (74.6\% vs 61.7\%), but this difference did not achieve statistical significance (log-rank $P=0.087$ ).

Conclusion: These results indicate that device type may affect RHF incidence and mortality. Studies at other centers are needed to replicate these findings.

Keywords: Heart-assist devices, heart failure, heart ventricles, renal dialysis, ventricular dysfunction-right, ventricular function-right

Address correspondence to Aditya Bansal, MD, Department of Cardiothoracic Surgery, Ochsner Clinic Foundation, 1514 Jefferson Hwy., New Orleans, LA 70121. Tel: (504) 842-3966. Email: adbansal@ochsner.org

\section{INTRODUCTION}

Mechanical circulatory support with a continuous-flow left ventricular assist device (LVAD) is mainstay therapy for patients with advanced-stage heart failure. The overall 1and 2 -year survival rates are $80 \%$ and $70 \%$, respectively, with the majority of patients experiencing improved physical status and quality of life. ${ }^{1}$ Following LVAD implantation, bleeding and infection are the most frequent adverse events, and right heart failure (RHF) is the leading cause of early death. ${ }^{2,3}$ Posttransplant outcomes are worse for patients who develop RHF during LVAD support. ${ }^{4}$ Adequate right heart function is essential to maintain sufficient cardiac output and perfusion of organ systems. Poor right ventricular function and/or high pulmonary vascular resistance may severely impair left heart filling, resulting in low cardiac out- put despite a properly functioning LVAD. Avoidance of RHF following LVAD implantation is important to optimize the outcomes of LVAD-supported patients.

The interaction of the right heart with LVAD support has been of great interest to clinicians since the early use of mechanical circulatory support. ${ }^{5-9}$ In late-stage heart failure with global myocardial dysfunction, chronically elevated left heart pressures produce pulmonary hypertension, increasing the vulnerability of right heart function. Following LVAD implant, right heart function is further compromised in patients who experience decreased renal, hepatic, and pulmonary function with a concomitant significant increase in mortality. Houston et al showed that the increased cardiac output and lower left ventricular pressure from LVAD support increased right ventricular preload with a leftward septal 
shift, enlarged the right ventricle, and decreased right ventricular contractility. ${ }^{10}$ Maintaining adequate systemic perfusion and avoiding right heart dysfunction require careful management of intravascular volume with either inotropic or mechanical support of right heart function.

At our center, we sought to identify reasons for the high mortality in our population of patients supported by durable LVADs. RHF occurrence and LVAD type were variables that required examination. The purpose of this study was to assess the impact of perioperative variables and the type of LVAD on the incidence of RHF and survival.

\section{METHODS}

This single-center retrospective study involved all consecutive patients $(n=184)$ implanted with a continuous-flow LVAD from January 2012 to June 2016 for the indications of bridge to transplant and destination therapy. Patients with advanced-stage heart failure were implanted with either the HeartMate II LVAD (Abbott) or the HeartWare ventricular assist device (HVAD) (Medtronic). The Ochsner Clinic Foundation Institutional Review Board approved the study.

Patient data collected for analysis included demographics, indication for support, Interagency Registry for Mechanically Assisted Circulatory Support (INTERMACS) profile, New York Heart Association (NYHA) functional class, hemodynamics, medical history, and laboratory values. Postoperative data included reoperations for bleeding, delayed sternal closure, renal failure with the need for dialysis, and RHF. $\mathrm{RHF}$ was defined as the need for a right ventricular assist device (RVAD) or inotropic support for >14 days any time after LVAD implantation. Management of patients evolved somewhat over time as protocols were refined, while each cohort (HeartMate II and HVAD) was treated comparably. The manufacturers' recommended anticoagulation protocols were used, and guidelines published by the International Society of Heart Lung Transplantation were applied to all patients. ${ }^{11}$

Continuous variables are reported as mean \pm standard deviation and were compared with 2 -sided $t$ tests. Categorical variables are reported as number and percentage and were compared with chi-square or Fisher exact tests. Tests were considered significant at $P \leq 0.05$. Postoperative outcomes by implant were assessed by logistic regression via inverse probability weighting propensity score analysis with bootstrap-based standard errors and confidence limits. A set of 8 covariates (blood urea nitrogen [BUN], total bilirubin, creatinine, central venous pressure [CVP], pulmonary artery [PA] systolic pressure, left ventricular end diastolic diameter [LVEDD], preoperative intra-aortic balloon pump [IABP], and mechanical circulatory support prior to LVAD) were considered for the propensity model; a covariate was included in the propensity model only if it showed significance or an apparent change in estimated association (odds ratio [OR] in outcome by implant). Propensity matching was done to achieve the best comparison between the 2 groups, understanding the limitations of propensity matching with small cohorts. SAS v.9.4 (SAS Institute) was used for all analyses.

\section{RESULTS}

The sample consisted of 184 patients with end-stage heart failure who were implanted with either the HeartMate II $(n=161)$ or the HVAD $(n=23)$. Demographics, medical his- tory, and preoperative physiologic variables for all patients and those supported by the HeartMate II and the HVAD are provided in Table 1. The preoperative variables analysis indicates that the 2 groups were homogeneous. Most patients were classified as INTERMACS profile 1 or $2(92 \%)$ and NYHA class IV (81\%). More patients in the HeartMate II group had the indication of destination therapy (54\% vs $30 \%$ ), and more HVAD patients were implanted for bridge to transplant (70\% vs $46 \%)$; the difference between the groups was statistically significant $(P=0.04)$. The mean duration of LVAD support for the entire cohort was 682 days \pm 503 days.

INTERMACS profile, NYHA class, hemodynamics, preoperative mechanical circulatory support, and related medical history were not different between the 2 groups. The international normalized ratio was statistically higher for the HeartMate II group $(P=0.03)$, which may be explained by the higher proportion of patients being destination therapy candidates who often have extended heart failure care. Renal and hepatic function variables were not statistically different between the 2 groups.

Postoperatively, bleeding requiring reoperation occurred in $24 \%$ of patients with near equal occurrences in the HeartMate II (24\%) and HVAD (26\%) groups (Table 2). Delayed sternal closure rates were also similar between the 2 groups, as this practice is common in our institution as a strategy for right ventricular protection. Renal failure requiring dialysis occurred in $15 \%$ of all patients, with a higher frequency in patients who received the HVAD $(26 \%)$ than in the patients (14\%) who received the HeartMate II, but the difference was not statistically significant $(P=0.12)$. Overall, RHF requiring prolonged inotropic support occurred in 39 (21\%) patients. Of this group, 10 patients required RVAD support with a TandemLife device, utilizing the Protek Duo cannula (CardiacAssist, Inc.). The device was inserted through the right internal jugular vein in the cardiac catherization laboratory under fluoroscopy and transthoracic echocardiography guidance. No device complications were observed during RVAD support. The occurrence of RHF was statistically higher in HVAD-supported patients (57\%) compared to patients who received the HeartMate II (16\%) $(P<0.0001)$.

After propensity adjustment between device types, statistically significant associations between the type of device selected (HeartMate II vs HVAD) and the occurrence of RHF $(P=0.0013)$ and renal failure requiring dialysis $(P=0.0135)$ were observed. In both cases, the estimated chances of these events increased by $40 \%$ (95\% confidence interval $10 \%-90 \%$ for $\mathrm{RHF}$, and $0 \%-80 \%$ for renal failure requiring dialysis) for HVAD vs HeartMate II (Table 2).

A total of 59 (32\%) patients died during the follow-up period. An equal number of patients $(59,32 \%)$ underwent transplantation. The highest mortality occurred during the first year of the study (2012), with a rate of $46 \%$ that decreased to $21 \%$ in 2016 . In comparing survival between the types of LVAD, the survival rate of the HeartMate II group exceeded that of the HVAD group at 1 year $(82.1 \%$ vs $67.2 \%)$ and 2 years $(74.6 \%$ vs $61.7 \%)$, but this difference did not achieve statistical significance (log-rank $P=0.087$ ) (Figure).

\section{DISCUSSION}

In 2012, we recognized that our mechanical circulatory support program had a higher-than-expected mortality rate for patients supported by an LVAD. We implemented a 
Table 1. Preoperative Demographics and Clinical Status

\begin{tabular}{|c|c|c|c|c|}
\hline Variable & $\begin{array}{c}\text { All } \\
\text { Patients } \\
n=184\end{array}$ & $\begin{array}{c}\text { HeartMate II } \\
\text { Group } \\
n=161\end{array}$ & $\begin{array}{l}\text { HVAD } \\
\text { Group } \\
n=23\end{array}$ & P-Value \\
\hline Age, years, mean $\pm S D$ & $51.6 \pm 12.3$ & $51.6 \pm 12.4$ & $51.2 \pm 11.8$ & 0.89 \\
\hline Male, n (\%) & $133(72)$ & $119(74)$ & $14(61)$ & 0.22 \\
\hline Body mass index, $\mathrm{kg} / \mathrm{m}^{2}$, mean $\pm \mathrm{SD}$ & $28.8 \pm 5.2$ & $28.6 \pm 5.0$ & $30.1 \pm 6.4$ & 0.20 \\
\hline Indication, n (\%) & & & & 0.04 \\
\hline Bridge to transplant & $90(49)$ & $74(46)$ & $16(70)$ & \\
\hline Destination therapy & $94(51)$ & $87(54)$ & $7(30)$ & \\
\hline INTERMACS profile, n (\%) & & & & 0.56 \\
\hline 1 & $15(8)$ & $15(9)$ & 0 & \\
\hline 2 & $154(84)$ & $132(82)$ & $22(96)$ & \\
\hline 3 & $11(6)$ & $10(6)$ & $1(4)$ & \\
\hline 4 & $3(2)$ & $3(2)$ & 0 & \\
\hline 5 & $1(1)$ & $1(1)$ & 0 & \\
\hline NYHA class, n (\%) & & & & 0.50 \\
\hline II & $10(5)$ & $10(6)$ & 0 & \\
\hline III & $25(14)$ & $23(14)$ & $2(9)$ & \\
\hline IV & $149(81)$ & $128(80)$ & $21(91)$ & \\
\hline \multicolumn{5}{|l|}{ Hemodynamics } \\
\hline Cardiac index, $\mathrm{L} / \mathrm{m}^{2}$, mean $\pm \mathrm{SD}$ & $1.93 \pm 0.63$ & $1.93 \pm 0.65$ & $1.94 \pm 0.52$ & 0.96 \\
\hline Heart rate, bpm, mean \pm SD & $92.1 \pm 16.2$ & $92.1 \pm 16.4$ & $91.7 \pm 15.3$ & 0.91 \\
\hline CVP, $\mathrm{mmHg}$, mean $\pm \mathrm{SD}$ & $9.2 \pm 5.2$ & $9.2 \pm 5.2$ & $8.2 \pm 4.4$ & 0.46 \\
\hline $\mathrm{PCWP}, \mathrm{mmHg}$, mean $\pm \mathrm{SD}$ & $23.2 \pm 8.7$ & $23.0 \pm 8.3$ & $24.5 \pm 10.8$ & 0.50 \\
\hline $\mathrm{LVEF}, \%$, mean $\pm \mathrm{SD}$ & $15.5 \pm 5.4$ & $15.5 \pm 5.5$ & $15.9 \pm 5.1$ & 0.74 \\
\hline Preimplant MCS, n (\%) & $33(18)$ & $29(18)$ & $4(17)$ & 1.00 \\
\hline Intra-aortic balloon pump, n (\%) & $142(77)$ & $123(76)$ & $19(83)$ & 0.61 \\
\hline \multicolumn{5}{|l|}{ History, n (\%) } \\
\hline Diabetes & $79(43)$ & $68(42)$ & $11(48)$ & 0.66 \\
\hline Dyslipidemia & $84(46)$ & $75(47)$ & $9(39)$ & 0.66 \\
\hline Hypertension & $129(70)$ & $111(69)$ & $18(78)$ & 0.47 \\
\hline COPD & $44(24)$ & $38(24)$ & $6(26)$ & 0.80 \\
\hline Stroke & $22(12)$ & $20(12)$ & $2(9)$ & 1.00 \\
\hline \multicolumn{5}{|l|}{ Laboratory } \\
\hline INR, mean \pm SD & $1.17 \pm 0.31$ & $1.19 \pm 0.32$ & $1.04 \pm 0.09$ & 0.03 \\
\hline Total bilirubin, $\mathrm{mg} / \mathrm{dL}$, mean $\pm \mathrm{SD}$ & $1.10 \pm 0.71$ & $1.11 \pm 0.72$ & $1.04 \pm 0.65$ & 0.64 \\
\hline Creatinine, $\mathrm{mg} / \mathrm{dL}$, mean $\pm \mathrm{SD}$ & $1.26 \pm 0.62$ & $1.25 \pm 0.64$ & $1.31 \pm 0.42$ & 0.67 \\
\hline $\mathrm{BUN}, \mathrm{mg} / \mathrm{dL}$, mean $\pm \mathrm{SD}$ & $25.7 \pm 15.4$ & $29.6 \pm 16.8$ & $25.1 \pm 15.1$ & 0.25 \\
\hline MELD score & $11.0 \pm 4.4$ & $11.1 \pm 4.6$ & $10.2 \pm 3.1$ & 0.35 \\
\hline
\end{tabular}

BUN, blood urea nitrogen; COPD, chronic obstructive pulmonary disease; CVP, central venous pressure; HVAD, HeartWare ventricular assist device; INR, international normalized ratio; INTERMACS, Interagency Registry for Mechanically Assisted Circulatory Support; LVEF, left ventricular ejection fraction; MCS, mechanical circulatory support; MELD, Model for End-Stage Liver Disease; NYHA, New York Heart Association; PCWP, pulmonary capillary wedge pressure.

number of changes to meet the accepted guidelines for the care of patients receiving durable mechanical circulatory support. In the process of assessing our program, we identified RHF and the type of LVAD as variables affecting outcomes. Although our mortality rate decreased from $46 \%$ in 2012 to $21 \%$ in 2016 , it became apparent that the type of device might be affecting the incidence of RHF and survival.

Following LVAD implantation, RHF may occur early or late and is associated with poor survival. ${ }^{12}$ Risk factors associated with RHF include decreased renal and 
Table 2. Postoperative Outcomes

\begin{tabular}{|c|c|c|c|c|c|c|c|}
\hline Variable & $\begin{array}{c}\text { All } \\
\text { Patients } \\
n=184\end{array}$ & $\begin{array}{l}\text { HeartMate II } \\
\text { Group } \\
n=161\end{array}$ & $\begin{array}{l}\text { HVAD } \\
\text { Group } \\
n=23\end{array}$ & $\begin{array}{c}\text { Unadjusted } \\
\text { Odds Ratio } \\
\text { (Confidence Interval) }\end{array}$ & $P$-value & $\begin{array}{c}\text { Propensity-Adjusted } \\
\text { Odds Ratio } \\
\text { (Confidence Interval) }\end{array}$ & $P$-value \\
\hline Bleeding requiring reoperation & $44(24)$ & $38(24)$ & $6(26)$ & $1.1(0.4,3.1)$ & 0.7956 & $1.1(0.8,1.5)$ & 0.3799 \\
\hline Delayed sternal closure & $108(59)$ & $94(58)$ & $14(61)$ & $1.1(0.4,2.7)$ & 0.8209 & $0.9(0.7,1.2)$ & 0.4987 \\
\hline Renal failure with dialysis & $28(15)$ & $22(14)$ & $6(26)$ & $2.2(0.8,6.3)$ & 0.1208 & $1.4(1.0,1.8)$ & 0.0135 \\
\hline Right heart failure & $39(21)$ & $26(16)$ & $13(57)$ & $6.7(2.7,17.0)$ & $<0.0001$ & $1.4(1.1,1.9)$ & 0.0013 \\
\hline
\end{tabular}

${ }^{a}$ The following variables were used for the propensity-adjusted analysis: blood urea nitrogen, pulmonary artery systolic pressure, left ventricular end diastolic diameter, indication for implantation, and mechanical ventilation.

Frequency data are presented as $n$ (\%).

HVAD, HeartWare ventricular assist device.

hepatic function, high white blood cell count, increased CVP, increased CVP/pulmonary capillary wedge pressure ratio, tricuspid valve incompetence, and decreased stroke work index.4,10,13,14 To mitigate the selection bias in our study, propensity score analysis was used to estimate the association between outcomes and device type. Covariates that are known risk factors for RHF after LVAD implantation (BUN, total bilirubin, creatinine, CVP, PA systolic, LVEDD, preoperative IABP, and mechanical circulatory support prior to LVAD) were initially selected to build a propensity model. The final propensity model included 5 variables (indication for implantation, BUN, PA systolic, LVEDD, and mechanical ventilation) that achieved statistical significance or showed an apparent change in estimated association (OR in outcome by implant) (Table 2).

The HeartMate II LVAD and the HVAD are the most commonly used devices for bridge to transplant and destination therapy. Although both devices directly unload the left ventricle and provide similar levels of cardiac output support, some clinical differences have been observed. In the randomized ENDURANCE (The HeartWare Ventricular Assist System as Destination Therapy of Advanced Heart Failure)

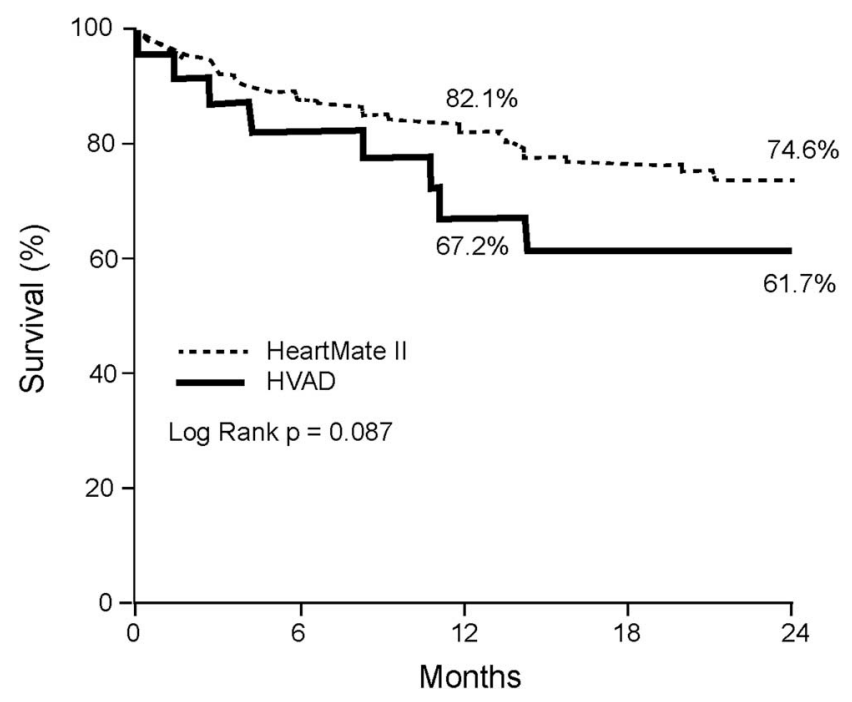

Figure. Kaplan-Meier survival analysis for the HeartMate II and HeartWare ventricular assist device (HVAD) groups. trial comparing these devices for destination therapy, the HVAD device had an overall RHF rate $11.7 \%$ higher than the HeartMate II. ${ }^{15}$ While the need for RVAD support was nearly equivalent between groups, prolonged inotropic support was necessary in more of the HVAD-supported patients. Our study findings concur with this result: $57 \%$ of patients in our HVAD group needed prolonged inotropic support compared to $16 \%$ of our patients in the HeartMate II group. Other studies report similar observations: an overall lower rate of RHF in the HeartMate II group and a similar need for an RVAD between devices. ${ }^{16-18}$ In contrast, other studies have observed no difference in RHF incidence or outcomes between the 2 devices. ${ }^{19-21}$ No clear mechanism explains the difference in outcomes between patients supported by the HeartMate II and HVAD devices. Both groups in our study were very similar preoperatively with regard to severity of illness and organ function. Postoperatively, all patients received the same level of care, suggesting that the type of device is the primary variable affecting the occurrence of $\mathrm{RHF}$ and mortality. Studies at other centers are needed to replicate these findings.

\section{Limitations}

This study has all the usual limitations inherent to a retrospective analysis. All patients were discussed in the multidisciplinary selection meeting for candidacy for mechanical circulatory support; however, differences in referral patterns and physician preferences may have affected the specific choice of a particular device. Another limitation of this study is the smaller number of patients in the HVAD group and limited availability of hemodynamic parameters that could be used for analysis. At our center, many changes have occurred with protocol-driven and standardized management of patients with heart failure over the years. These changes could have contributed to the improvement in the mortality rates. Also, our understanding of RHF has evolved tremendously, leading to better patient selection and early identification and management of RHF. These factors could also have contributed to the decrease in the incidence of $\mathrm{RHF}$ in the latter half of the study period.

\section{CONCLUSION}

Our understanding of RHF continues to evolve and has improved over the years. Multiple risk calculators for preoperative identification of RHF exist, but they have poor 
sensitivity. None of the calculators takes the type of device implanted into consideration. The results of our study indicate that the type of device may contribute to the development of RHF in patients undergoing LVAD implantation. Further studies are needed in a larger population with a focus on the hemodynamic differences between the 2 devices and reasons for the development of RHF.

\section{ACKNOWLEDGMENTS}

$A B$ has received speaking honoraria from Abbott, TandemLife, and Abiomed. JKB has received speaking honoraria from TandemLife and Abbott. $S D$ has received speaking honoraria from Abbott. Otherwise, the authors have no financial or proprietary interest in the subject matter of this article.

\section{REFERENCES}

1. Kirklin JK, Pagani FD, Kormos RL, et al. Eighth annual INTERMACS report: special focus on framing the impact of adverse events. J Heart Lung Transplant. 2017

Oct;36(10):1080-1086. doi: 10.1016/j.healun.2017.07.005.

2. Dang NC, Topkara VK, Mercando M, et al. Right heart failure after left ventricular assist device implantation in patients with chronic congestive heart failure. J Heart Lung Transplant. 2006 Jan;25(1):1-6. doi: 10.1016/j.healun.2005.07.008.

3. Takeda K, Naka Y, Yang JA, et al. Outcome of unplanned right ventricular assist device support for severe right heart failure after implantable left ventricular assist device insertion. $J$ Heart Lung Transplant. 2014 Feb;33(2):141-148. doi: 10.1016/j.healun.2013.06.025.

4. Takeda K, Takayama H, Colombo PC, et al. Late right heart failure during support with continuous-flow left ventricular assist devices adversely affects post-transplant outcome. J Heart Lung Transplant. 2015 May;34(5):667-674. doi: 10.1016/j.healun.2014.10.005.

5. Farrar DJ, Compton PG, Hershon JJ, Fonger JD, Hill JD. Right heart interaction with the mechanically assisted left heart. World J Surg. 1985 Feb;9(1):89-102.

6. Farrar DJ, Chow E, Compton PG, Foppiano L, Woodard J, Hill JD. Effects of acute right ventricular ischemia on ventricular interactions during prosthetic left ventricular support. J Thorac Cardiovasc Surg. 1991 Oct;102(4):588-595.

7. Van Meter CH Jr, Robbins RJ, Ochsner JL. Technique of right heart protection and deairing during HeartMate vented electric LVAD implantation. Ann Thorac Surg. 1997 Apr;63(4):1191-1192.

8. Dang NC, Mercando ML, Kay J, et al. Right heart failure following left ventricular assist device implantation. J Heart Lung Transplant 2005;24:S147.

9. Patel ND, Weiss ES, Schaffer J, et al. Right heart dysfunction after left ventricular assist device implantation: a comparison of the pulsatile HeartMate I and axial-flow HeartMate II devices. Ann Thorac Surg. 2008 Sep;86(3):832-840; discussion 832-840. doi: 10.1016/j.athoracsur.2008.05.016.

10. Houston BA, Shah KB, Mehra MR, Tedford RJ. A new "twist" on right heart failure with left ventricular assist systems. J Heart Lung Transplant. 2017 Jul;36(7):701-707. doi: 10.1016/j.healun.2017.03.014.

11. Feldman D, Pamboukian SV, Teuteberg JJ, et al. The 2013 International Society for Heart and Lung Transplantation guidelines for mechanical circulatory support: executive summary. J Heart Lung Transplant. 2013 Feb;32(2):157-187. doi: 10.1016/j.healun.2012.09.013.

12. Kormos RL, Teuteberg JJ, Pagani FD, et al. Right ventricular failure in patients with the HeartMate II continuous-flow left ventricular assist device: incidence, risk factors, and effect on outcomes. J Thorac Cardiovasc Surg. 2010

May;139(5):1316-1324. doi: 10.1016/j.jtcvs.2009.11.020.

13. Lee S, Kamdar F, Madlon-Kay R, et al. Effects of the HeartMate II continuous-flow left ventricular assist device on right ventricular function. $J$ Heart Lung Transplant. 2010 Feb;29(2):209-215. doi: 10.1016/j.healun.2009.11.599.

14. Fida N, Loebe M, Estep JD, Guha A. Predictors and management of right heart failure after left ventricular assist device implantation. Methodist Debakey Cardiovasc J. 2015 Jan-Mar;11(1):18-23.

15. Rogers JG, Pagani FD, Tatooles AJ, et al. Intrapericardial left ventricular assist device for advanced heart failure. $N$ Engl J Med. 2017 Feb 2;376(5):451-460. doi: 10.1056/NEJMoa1602954.

16. Lalonde SD, Alba AC, Rigobon A, et al. Clinical differences between continuous flow ventricular assist devices: a comparison between HeartMate II and HeartWare HVAD. J Card Surg. 2013 Sep;28(5):604-610. doi: 10.1111/jocs.12158.

17. Stulak JM, Davis ME, Haglund N, et al. Adverse events in contemporary continuous-flow left ventricular assist devices: a multi-institutional comparison shows significant differences. J Thorac Cardiovasc Surg. 2016 Jan;151(1):177-189. doi: 10.1016/j.jtcvs.2015.09.100.

18. Turer DM, Koch KL, Koelling TM, Wu AH, Pagani FD, Haft JW. Comparing the effectiveness of an axial and a centrifugal left ventricular assist device in ventricular unloading. ASAIO J. 2016 Nov/Dec;62(6):652-656. doi: 10.1097/MAT.0000000000000420.

19. Sabashnikov A, Mohite PN, Zych B, et al. Outcomes in patients receiving HeartMate II versus HVAD left ventricular assist device as a bridge to transplantation. Transplant Proc. 2014 Jun;46(5):1469-1475. doi: 10.1016/j.transproceed.2013.12.057.

20. Kurihara C, Critsinelis AC, Kawabori M, et al. Frequency and consequences of right-sided heart failure after continuous-flow left ventricular assist device implantation. Am J Cardiol. 2018 Feb 1;121(3):336-342. doi: 10.1016/j.amjcard.2017.10.022.

21. Morgan JA, Go PH, Xuereb L, et al. Outcomes on continuous flow left ventricular assist devices: a single institutional 9-year experience. Ann Thorac Surg. 2016 Oct;102(4):1266-1273. doi: 10.1016/j.athoracsur.2016.03.026.

This article meets the Accreditation Council for Graduate Medical Education and the American Board of Medical Specialties Maintenance of Certification competencies for Patient Care, Medical Knowledge, and Practice-Based Learning and Improvement. 